\title{
Um Desvio Inesperado
}

\section{An Unexpected Turn}

Gonçalo Videira ${ }^{1, \star}$, Hugo Mota Dória ${ }^{2}$, Manuel Correia ${ }^{1}$, Carlos Andrade ${ }^{1}$

1-Serviço de Neurologia, Centro Hospitalar Universitário do Porto, Porto, Portugal

2-Serviço de Neurorradiologia do Centro Hospitalar Universitário do Porto, Porto, Portugal

DOI: https://doi.org/10.46531/sinapse/IN/210012/2021

\section{Caso}

Um homem de 42 anos foi observado na sala de emergência uma hora após a instalação abrupta de cefaleia seguida de perda de consciência. Dos antecedentes pessoais destacavam-se hipertensão arterial não tratada há 10 anos, tabagismo significativo e perturbação de uso de álcool. À admissão apresentava-se sonolento, não verbalizando ou cumprindo ordens, com limitação superior do olhar e localizando dor com a mão esquerda. A tomografia computorizada (TC) crânio-encefálica revelou um hematoma intraparenquimatoso talâmico esquerdo, com rotura para o sistema ventricular e sinais de hidrocefalia (Fig. 1); o estudo angiográfico não evidenciou anomalias vasculares. Foi admitido na Unidade de Cuidados Intensivos após colocação de uma derivação ventricular externa frontal esquerda.

Três semanas depois apresentava afasia de predomínio motor e hemiparesia direita homogénea e espástica. $\bigcirc$ exame oculomotor era marcado por ptose palpebral bilateral e desvio conjugado persistente do olhar para a direita no olhar primário, que se mantinha durante estímulos verbais e revertia com o reflexo oculocefálico (Fig. 2, Vídeo) - um wrong-way deviation. O achado desvaneceu ao fim de uma semana, mantendo-se a limitação dos movimentos oculares superiores e da

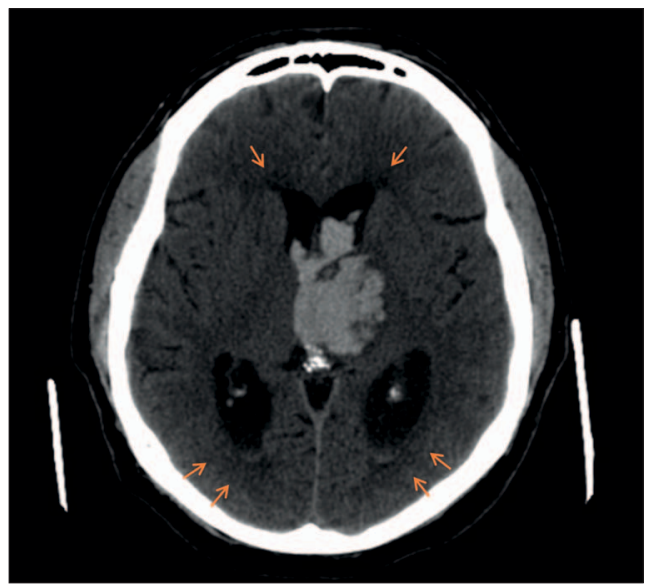

Figura 1. Imagem axial de TC crânio-encefálico.

Observa-se hemorragia intra-axial centrada no tálamo esquerdo com extensão às estruturas adjacentes e rotura para o sistema ventricular. É também notória uma dilatação dos ventrículos laterais e diminuição da densidade da substância branca peri-ventricular (setas), achados que são compatíveis com hidrocefalia em evolução e consequente transudação ependimária.

\section{Figura 2 e Vídeo. Wrong-way deviation.}

Observa-se desvio conjugado persistente do olhar para a direita no olhar primário e durante a estimulação verbal, sendo incapaz de fixar o examinador atrás da câmara. Era necessária abertura passiva das pálpebras. Não foram visualizados seguros movimentos involuntários.
Informações/Informations: Imagem em Neurologia, publicado em Sinapse, Volume 21, Número 2, abril-junho 2021. Versão eletrónica em www.sinapse.pt Image in Neurology, published in Sinapse, Volume 21, Number 2, April-June 2021. Electronic version in www.sinapse.pt (C) Autor (es) lou seu (s) empregador (es)) e Sinapse 2021. Reutilização permitida de acordo com CC BY-NC. Nenhuma reutilização comercial. (C) Author(s) (or their employer(s)) and Sinapse 2021. Re-use permitted under CC BYNC. No commercial re-use.

\section{Palavras-chave:}

Acidente Vascular Cerebral; Perturbações da Motilidade Ocular.

\section{Keywords:}

Ocular Motility Disorder; Stroke.

\section{*Autor Correspondente / Corresponding Author: Pedro Gonçalo de Medeiros Videira \\ Serviço de Neurologia, CHUP Largo do Prof. Abel Salazar, 4099-001 Porto, Portugal pgoncalomv@gmail.com}

Recebido / Received: 2021-02-15 Aceite / Accepted: 2021-04-14 Publicado / Published: 2021-07-29 
abertura das pálpebras. Uma vez que toda a fenomenologia se enquadrava na lesão tálamo-mesencefálica descrita, e atendendo à ausência de lesões com potencial epileptogéneo, não foi realizado eletroencefalograma.

O fenómeno de wrong-way deviation tem sido raramente descrito. ${ }^{1-3}$ Caracteriza-se pelo desvio do olhar no sentido contrário ao do hemisfério afetado e na sua génese estão geralmente hemorragias talâmicas ou enfartes cerebrais extensos com compressão do tronco cerebral. ${ }^{2}$ Uma das teorias explicativas afirma que uma lesão supratentorial com efeito de massa significativo pode lesionar as vias oculomotoras sacádicas descendentes que decussam no mesencéfalo rostral e terminam na ponte contralateral. ${ }^{2,3} \mathrm{~A}$ lesão das fibras que já decussaram pode assim resultar num desvio contralateral do olhar. ${ }^{3}$ Outra explicação inclui a disfunção dos movimentos de perseguição ipsilaterais observável em associação a lesões parieto-occipitais ipsilaterais, e que pode raramente resultar no desvio contralateral do olhar. $^{3-5} \bigcirc$ facto de este fenómeno ocorrer vários dias após o acidente vascular cerebral - quando o edema é mais significativo - concorda com estas hipóteses. ${ }^{2}$

Uma vez que o wrong-way deviation pode ser confundível com outras causas de desvio contralateral do olhar em doentes com baixo nível de consciência, o seu reconhecimento é importante.

\section{Responsabilidades Éticas}

Conflitos de interesse: Os autores declaram inexistência de conflitos de interesse.

Fontes de financiamento: Não existiram fontes externas de financiamento.

Confidencialidade dos dados: Os autores declaram ter seguido os protocolos da sua instituição acerca da publicação dos dados de doentes.

Consentimento: Consentimento do doente para publicação obtido.

Proveniência e revisão por pares: Não comissionado; revisão externa por pares.

\section{Ethical Disclosures}

Conflicts of interest: The authors have no conflicts to declare. Financing support: This work has not received any financing support.

Confidentiality of data: The authors declare that they followed the guidelines of their center on the publication of patient data.

Patient consent: Consent for publication was obtained.

Provenance and peer review: Not commissioned; external peer-review.

\section{References / Referências}

1. Messe SR, Cucchiara BL. Wrong-way eyes with thalamic hemorrhage. Neurology. 2003;60:1524. doi: 10.1212/01. wnl.0000065900.62880.4f.

2. Johkura K, Nakae Y, Yamamoto R, Mitomi M, Kudo Y. Wrong-way deviation: contralateral conjugate eye deviation in acute supratentorial stroke. J Neurol Sci. 2011;308:1657.doi: 10.1016/j.jns.2011.06.010.

3. Tijssen CC. Contralateral conjugate eye deviation in acute supratentorial lesions. Stroke. 1994;25:1516-9. doi: 10.1161/01.str.25.7.1516.

4. Tanaka H, Arai M, Kubo J, Hirata K. Conjugate eye deviation with head version due to a cortical infarction of the frontal eye field. Stroke. 2002;33:642-3. doi: 10.1161/str.33.2.642.

5. Singer OC, Humpich MC, Laufs $H$, Lanfermann H, Steinmetz $\mathrm{H}$, Neumann-Haefelin T. Conjugate eye deviation in acute stroke: incidence, hemispheric asymmetry, and lesion pattern. Stroke. 2006;37:2726-32. doi: 10.1161/01. STR.0000244809.67376.10. 